\title{
Orthographic onsets and rimes as functional units of reading
}

\author{
JUDITH A. BOWEY \\ University of Queensland, St. Lucia, Queensland, Australia
}

\begin{abstract}
Three experiments are described in which a partial identity priming procedure was used to investigate the hypothesis that orthographic onsets and rimes serve as units of visual word recognition. In Experiment 1, partial identity priming using word-final trigrams was observed only when the trigram constituted the orthographic rime unit. Nonrime trigrams were ineffective primes. In Experiment 2, partial identity priming using word-final bigrams in which both experimental and control primes were similar in bigram frequency was observed only when the bigram corresponded to the orthographic rime unit. Nonrime primes were again ineffective primes. In Experiment 3, partial identity priming using word-initial bigrams was observed only when the bigram corresponded to the orthographic onset unit. Non-onset bigrams were ineffective primes. These differential priming outcomes cannot be explained by graphemic priming, prime frequency, or practice effects. They are consistent with the hypothesis that syllable onset and rime units serve as functional units of reading.
\end{abstract}

Until relatively recently, there were two main classes of theory of visual word recognition, the dual-access model (e.g., Coltheart, 1978) and models based on single lexical mechanisms (e.g., Glushko, 1979; Marcel, 1980; McClelland \& Rumelhart, 1981). However, it has become apparent that neither class of theory can accommodate all of the available empirical data. For instance, single lexical mechanism theories of word recognition cannot readily account for the fact that the orthographic consistency effect is observed only in low-frequency words (Andrews, 1982; Seidenberg, Waters, Barnes, \& Tanenhaus, 1984). However, the consistency effect per se cannot be explained by a dual-access account that focuses primarily on graphemic units corresponding to single graphemes (e.g., Coltheart, 1985). Nor can the dualaccess model explain how procedures that boost the activation levels of exception neighbors (e.g., presenting exception words prior to inconsistent regular targets) increase the magnitude of the consistency effect (Kay \& Marcel, 1981; Seidenberg et al., 1984; Taraban \& McClelland, 1987).

In recent years, a third class of multilevel model has arisen, in which it is proposed that words are processed at a number of levels in parallel (e.g., Patterson \& Morton, 1985; Shallice \& McCarthy, 1985; see also Drewnowski \& Healy, 1977). Skilled readers can potentially access a variety of functional spelling units, ranging from the word (in high-frequency words), to inflec-

This research was funded by the Australian Research Grants Scheme (Grant A78615206) and the Australian Research Council (Grant A78832058). I would like to thank Julie Hansen and Robert dal Santo for their assistance with testing and programming. Address for correspondence: J. A. Bowey, Department of Psychology, University of Queensland, St. Lucia, Queensland 4067, Australia. tional morphemes (Drewnowski \& Healy, 1980), in addition to single letters.

Within this framework, particular attention has been directed to so-called "large-unit pronunciation rules" (see Patterson \& Morton, 1985; Shallice \& McCarthy, 1985) of reading, which correspond to syllable rime units proposed independently by linguists (see Fudge, 1987). Linguists view the English syllable as having an ordered and hierarchical internal structure, being composed of an (optional) onset unit and a rime unit. The onset unit consists of the (optional) consonant group at the beginning of a syllable (e.g., /s/ in save, or /sk/ in sky). The rime unit consists of the vowel and the (optional) final consonant group (e.g., /ev/ in save and /al/ in sky). The rime is further divided into a peak (the vowel nucleus) and an (optional) coda. It may be noted that some linguists claim that the syllable consists of three components at the same level-the onset, the peak, and the coda (e.g., Clements \& Keyser, 1983; but see Fudge, 1987). Linguistically, the division of the syllable into onset and rime accounts for both distributional phenomena (Fudge, 1987) and stress assignment (Chomsky \& Halle, 1968). However, there is also a growing body of evidence concerning syllable onset and rime as units of psychological processing: syllable onset and rime function as "psychologically real" units of speech perception (Cutler, Butterfield, \& Williams, 1987) and production (Claxton, 1974; MacKay, 1972). Clear evidence for the psychological reality of onset and rime units has been observed in studies of rulelearning (Treiman, 1983, 1985) and short-term memory (Treiman \& Danis, 1988).

However, until very recently, evidence that the rime also serves as a functional unit of reading has been largely indirect. For instance, although there is considerable evidence that the number of words with similar orthographic 
rime units influences word-recognition processes (Brown, 1987; Kay \& Bishop, 1987; Rosson, 1985), this evidence does not itself demonstrate the existence of orthographic rimes as units of reading. Similar effects can be predicted for other word segments (Seidenberg, 1988).

The first direct evidence of orthographic onsets and rimes as functional units of adult word recognition was supplied by Treiman and Chafetz (1987). They presented subjects with a series of anagram tasks. Given four fragments of words, and asked to judge whether or not two fragments could be combined to yield an English word, subjects responded more quickly, and made fewer errors, if the fragments making up the word corresponded to syllable onset and rime, rather than to arbitrary divisions of the word. For instance, subjects could judge that the series FL OST ANK TR contained fragments that made a word (flank) more quickly than when the fragments making up the word were not divided into orthographic onset and rime units (FLA ST NK TRO). In a further experiment, Treiman and Chafetz presented subjects with fiveletter words, into which two slashes were inserted after either the second or the third letter. The breaks following the second letter marked onset-rime boundaries, but the breaks following the third letter always interrupted the rime unit. Faster lexical decision times were observed when the slashes were inserted between onset and rime units (e.g., CR//ISP) than when they were not (e.g., $\mathrm{CRI} / \mathrm{SP}$ ).

Taraban and McClelland (1987) required subjects to name a pseudoword that was presented in conjunction with a real word that shared some letters (e.g., sail-saip). In contrast to Treiman and Chafetz's (1987) "orthographic rime" proposal, they observed equivalent facilitative priming effects in prime-target pairs such as sail-saip (beginning primes) and paid-yaid (rime primes). However, they also observed that primed pseudowords were more likely to be given an exception pronunciation if they were primed by exception rime primes than if they were preceded by regular inconsistent primes (see also Kay \& Marcel, 1981; Seidenberg et al., 1984; and see Treiman \& Zukowski, 1988). This effect was attenuated in the beginning prime condition. On the basis of this result, Taraban and McClelland concluded that the priming effects for the rime-prime condition were stronger than those obtained for the beginning prime condition and, following Treiman and Chafetz, suggested that rime units are probably more "natural" orthographic units. However, they also noted that the stronger effect for rime primes could be due to a tendency to produce responses that rhymed with the prime word. This suggestion could also account for Goswami's (1986) findings that even prereaders, given the pronunciation of a prime word that shared the rime (and pronunciation) of the target word, would often "read" the target word correctly.

The present research was designed to provide further evidence that orthographic onset and rime units may serve as functional units of adult word recognition by contrast- ing primes that are identical in all but orthographic onset/rime unit status. The three experiments described all used a "partial identity" priming paradigm. The rationale of this paradigm is that prior presentation of a prime that corresponds to the functional representation of the target word required for word recognition will facilitate word naming, relative to a control condition in which the word is not primed. Given this assumption, it follows that any differential effectiveness of partial primes as a function of their subsyllabic unit status would indicate that those subsyllabic units serve as functional units of word recognition. In contrast, a graphemic priming account would not predict differential priming effects, since both sets of primes share the same number of letters with the target word. Orthographic unit effects were examined in relation to the recognition of low-frequency words. This decision was based on previous findings that the orthographic consistency effect is more robust in low-frequency than in high-frequency words (Andrews, 1982; Seidenberg et al., 1984). It thus seemed more likely that subsyllabic unit effects would be obtained in low-frequency words than in high-frequency words.

\section{EXPERIMENT 1}

Experiment 1 was designed to determine whether or not the effectiveness of priming varied with the rime unit status of the prime. All target words were four letters in length. In half of these words, the syllable onset unit corresponded to a single letter. The remaining three letters comprised the orthographic rime unit. These words constituted the experimental words. Control words all had a two-letter onset unit, with the final two letters of the word corresponding to the orthographic rime unit. Each subject saw each target word twice, once primed by the final three letters of the word and once unprimed. Thus, the primes of the experimental words corresponded to orthographic rime units, whereas the primes of the control words did not correspond to any subsyllabic unit. Half of both the experimental and the control words were first seen primed; the other half were first presented unprimed. Thus, each word served as its own articulation latency control, and priming effects were computed in terms of the difference in naming latency between unprimed and primed conditions.

The beginning primes used by Taraban and McClelland (1987) actually primed the onset and vowel of the syllable (sail-saip). In Experiment 1, a more appropriate nonrime control was employed-that is, an equivalent word-final segment that did not correspond to a rime unit. The orthographic rime hypothesis would predict that priming would facilitate word naming in the experimental words (in which the prime corresponded to the rime unit) more strongly than in the control words (in which the prime did not correspond to a subsyllabic unit). A graphemic priming account would predict equal facilitation of both sets of words (as was observed by Taraban 
and $\mathrm{McClelland}$ in comparing beginning and rime primes), since in both sets the prime consisted of the final three letters of the target word.

\section{Method}

Subjects. Forty undergraduate students at the University of Queensland served as subjects in this experiment in order to gain credit toward an introductory psychology course. All were native English speakers.

Materials. Two parallel sets of materials were constructed for the experiment proper, derived from $\mathbf{4 0}$ low-frequency four-letter words (range 1-15 per 1,014,232; Kucera \& Francis, 1967). The 20 experimental words had a single consonant as their onset and a three-letter rime unit; the $\mathbf{2 0}$ control words comprised a two-letter onset unit followed by a two-letter rime (see Appendix 1). Thus, the rime unit of the experimental words was three letters in length; in the control words, it was two letters in length. Experimental and control word sets were equivalent in terms of word frequency according to the Kuxera and Francis (1967) word count $(M=12.15$ and 11.25 , respectively).

Two master word lists were then constructed, each containing the $\mathbf{4 0}$ target words in random order. Half of the experimental words and half of the control words on List 1 were randomly selected to be primed with the final three letters of the word; the other 10 were not primed. In List 2 , the target words that were not primed on List 1 were primed, while the words primed on List 1 were not primed on List 2 . In the experimental word set, the prime corresponded to the rime unit, but in the control words, the prime did not correspond to a subsyllabic unit.

Two sets of materials were then constructed. In Set 1, List 1 items constituted the first half of the materials (Block 1), and List 2 items comprised the second half (Block 2). In Set 2, List 2 items constituted the first half of the items (Block 1), and List 1 items comprised the second half (Block 2). Half of the subjects received each set of experimental materials.

An independent set of 20 practice items was prepared in a similar manner. The order of these practice items was randomized. No practice item was repeated either within the practice trials or within the blocks of test trials. All subjects received the same practice trials, in the same order.

Procedure. Each subject was tested individually. The experiment was controlled by a Commodore Amiga microcomputer (Model 1000). The stimuli were presented in white lower-case letters against a dark blue background on a Commodore Amiga color monitor (Model 1081). The subjects wore a headpiece to which a small microphone was attached. The microphone was connected to a voice key that interfaced with the computer. Response latencies were timed by the computer $\mathrm{I} / \mathrm{O}$ card, with naming latencies timed from the onset of the target word.

The subjects were told that they would very briefly see, in the center of the screen, a series of letters, which would be followed very briefly by a series of asterisks. The asterisks would in turn be followed by the presentation of a target word that would stay on the screen until it was named. Their task was to read the word aloud as quickly and as accurately as possible. They were asked to speak clearly, in order to ensure that the voicebox was triggered. Although the subjects were aware that the first set of trials constituted practice trials, they were instructed to respond as fast and as accurately as possible from the start.

All stimuli were presented in the center of the monitor. The prime, consisting of the final three letters of the target word (or a series of three asterisks, in the unprimed condition), was presented for $120 \mathrm{msec}$. This prime (or asterisk series) was then masked by a series of three asterisks, which was presented for a further $120 \mathrm{msec}$. The mask was followed by the presentation of the target word for up to $5 \mathrm{sec}$, with target word presentation terminated by activation of the voice key. If the voice key was not triggered, the target word remained on the screen for a maximum of $5 \mathrm{sec}$.

Immediately following target word offset, a question-mark prompt appeared on the screen. The research assistant then registered the status of the trial. A trial was regarded as invalid if the voicebox failed to register a naming response, if the voicebox had been activated by a non-naming response (such as a cough), or if the target word had been inappropriately identified. Data from invalid trials were subsequently discarded (see below). Following a pause of $3.5 \mathrm{sec}$, the next trial commenced.

The subjects were given a series of 20 practice trials before the test trials commenced. The first 12 practice trials were repeated if there were any problems with microphone adjustment or in voicebox functioning, or if the subjects appeared to misunderstand any aspect of the procedure.

\section{Results}

Only valid trials for which correct responses were made in $2 \mathrm{sec}$ or less were included in the data analysis. A total of 156 invalid trials $(4.9 \%)$ were discarded, due to failure to trigger the voice key, activation of the voice key through coughing or some other invalid response, error, or out-of-range responding.

Three-way, prime (primed, unprimed) $\times$ prime rime status (experimental, control) $\times$ block $(1,2)$, analyses of variance were computed on the data obtained from all valid trials, with both subject and item means as units. A significant main effect of priming was observed, with primed targets named more quickly than unprimed targets in both the subjects analysis $[F(1,39)=17.93, p<$ $.001]$ and the items analysis $[F(1,38)=8.22, p<.01]$ (see Table 1). The main effect of prime rime status was also significant in both the subjects analysis $[F(1,39)=$ $61.24, p<.001]$ and the items analysis $[F(1,38)=$ $17.98, p<.001]$. Overall, experimental words were named more quickly than control words.

However, both main effects were attributable to the predicted prime $\times$ prime rime status interaction, which was significant in both the subjects analysis $[F(1,39)=$ $15.30, p<.001]$ and the items analysis $[F(1,38)=7.61$, $p<.01]$. Simple-effects analyses showed that priming had a significant effect only when the prime constituted a rime unit, in both the subjects analysis $[F(1,39)=$ $44.71, p<.001]$ and the items analysis $[F(1,19)=$ 23.76, $p<.001$ ] (see Table 1). Nonrime primes had no

Table 1

Target Word Naming Latency (in milliseconds) in Experiment 1 as a Function of Prime Condition and Prime-Rime Unit Status

\begin{tabular}{lccccccc} 
& \multicolumn{3}{c}{ Unprimed } & & \multicolumn{3}{c}{ Primed } \\
\cline { 2 - 4 } \cline { 6 - 8 } Target Words & $M$ & $S D$ & Invalid & $M$ & $S D$ & Invalid \\
\hline Experimental & 577.28 & 73.43 & $3.3 \%$ & & 553.61 & 72.46 & $3.6 \%$ \\
Control & 597.08 & 78.10 & $6.5 \%$ & & 594.49 & 82.77 & $4.4 \%$ \\
\hline
\end{tabular}

Note-Invalid trials include out-of-range responses, voicebox malfunction, and reading errors. 
effect on word-naming latency (subjects and items analyses, $F s<1$ ).

The main effect of block was significant in both the subjects analysis $[F(1,39)=21.54, p<.001]$ and the items analysis $[F(1,38)=72.39, p<.001]$. Faster naming responses were observed in Block 2 than in Block 1. However, no interactions involving the block factor approached significance (all $p \mathrm{~s}>.05$ ).

\section{Discussion}

Overall, the experimental words were named more quickly than the control words, and priming produced shorter word-naming latencies relative to the unprimed condition. The significant main effects of prime and prime rime status both reflected the underlying prime $\times$ prime rime status interaction.

The unprimed condition was included to control for differences in the time taken to identify and articulate experimental and control target words, and as a baseline against which to examine priming effects. The simpleeffects analyses of the prime $\times$ prime rime status interaction compared naming latencies to primed and unprimed target words (1) when the prime corresponded to a rime unit and (2) when the prime did not correspond to any subsyllabic unit. Significant priming effects (relative to the unprimed condition) occurred only when the prime constituted an orthographic rime unit. No facilitation of word naming occurred when the prime did not correspond to a unit of syllable structure, even though those primes also comprised the final trigram of the target word.

Since all primes (rime and nonrime) were made up of the final three letters of the target word, the selective facilitation of rime priming cannot be explained in terms of graphemic priming effects. Similarly, since all primes, both rime and nonrime, rhymed with the target word, the rime-priming effect cannot be explained in terms of tendencies to provide rhyming responses. Nor can the differential priming effect be attributed to practice effects. Although naming latencies were shorter in Block 2 than in Block 1, the block factor did not interact with either (or both) prime or prime rime status factors. In particular, the absence of a prime $\times$ prime rime status $\times$ block interaction indicated that the differential priming effect was just as strong when the item first appeared as when it appeared for the second time. Thus, the differential priming effect cannot be explained in terms of practice effects.

In Experiment 1, the mean trigram frequency of the rime primes was marginally higher than that of the nonrime primes $[t(18)=2.99, p<.10]$, with means of $1,835.05$ and $1,009.85$ per $1,014,232$, respectively (Solso, Barbuto, \& Juel, 1979). A similar result was obtained using the Mayzner, Tresselt, and Wolin (1965) count $[t(18)=2.60, p<.10]$, with means for experimental and control primes of 32.05 and 18.15 per 20,000 , respectively. It is thus conceivable that the differential rime-priming effect observed in Experiment 1 reflected trigram frequency effects.

\section{EXPERIMENT 2}

Using the partial identity priming task, in Experiment 2 the orthographic rime hypothesis was again tested, this time using materials in which rime and nonrime primes had equivalent frequencies. Again, all target words were four letters long. The experimental words had two-letter rime units. The control words had three-letter rime units that ended with a two-letter consonant cluster. The incomplete rime units used in Experiment 2 correspond to what some linguists regard as a more viable unit than the rime (e.g., see Clements \& Keyser, 1983; but see Fudge, 1987). The coda consisted of the final consonant group (e.g., /st/ in grist). Thus, the primes of the experimental words corresponded to rime units, whereas the primes of the control words corresponded to hypothesized coda units. The use of a coda as the prime for the control words renders the present experiment a conservative test of the rime as a functional unit of word recognition.

The orthographic rime hypothesis would predict that priming would facilitate word-naming responses in the experimental words (in which the prime corresponded to the rime unit) more strongly than in the control words (in which the prime corresponded to a coda unit). Both graphemic priming and bigram frequency accounts would predict equal facilitation of both sets of words, since in all cases the prime consisted of the final two letters of the target word and prime frequencies were equivalent for the two sets of primes. The proposal that the coda corresponds to a subsyllabic unit, whereas the rime is unnecessary, would predict differential priming, but with stronger priming in the control words.

\section{Method}

Subjects. An independent sample of 30 students was recruited from the University of Queensland introductory psychology subject pool. Again, all were native English speakers.

Materials. Two parallel sets of materials were constructed for the experiment proper, derived from 32 low-frequency four-letter words (range 1-16; Kučera \& Francis, 1967). The 16 experimental words had a consonant cluster as their onset and a two-letter rime unit; the 16 control words comprised a single-letter onset followed by a three-letter rime (see Appendix 2). Experimental and control word sets were equivalent in terms of word frequency according to the Kučera and Francis (1967) word count $(M=6.50$ and 5.94, respectively). The mean bigram frequencies (Solso \& Juel, 1980) of the experimental and control primes were 10,520 and 9,445 (per 897,435), respectively. These were not significantly different $(t<1)$. The experimental and control words were also equivalent in bigram frequency in terms of the Mayzner and Tresselt (1965) count $(t<1)$, with means of 222.25 and 186.06 per 20,000 , respectively.

The method of construction of the two parallel sets of test materials was the same as that described in Experiment 1, with the exception that in the prime condition, words were primed with the wordfinal bigram. As in Experiment 1, half of the subjects received each set of experimental materials.

An independent set of 16 practice items was prepared in a similar manner. The order of the practice items was randomized. No practice item was repeated either within the practice trials or within the blocks of test trials. All subjects received the same practice trials, in the same order. 
Procedure. The procedure was identical to that used in Experiment 1 , except that the number of practice trials was reduced to 16 .

\section{Results}

Again, only correct and valid trials with naming latencies of $2 \mathrm{sec}$ or less were used in the data analysis. Only 103 trials $(5.36 \%)$ were discarded.

A three-way prime $\times$ prime rime status $\times$ block analysis of variance was performed on mean naming latency scores. Primed trials did not differ from unprimed trials overall, in either the subjects analysis $[F(1,29)=3.37$, $p>.05]$ or the items analysis $[F(1,30)=1.89$, $p>.05]$. Prime rime status was significant in the subjects analysis $[F(1,29)=5.59, p<.05]$, but not in the items analysis $[F(1,30)=1.83, p>.05]$. The prime rime status effect in the subjects analysis was attributable to the prime $\times$ prime rime status interaction, which was significant in both the subjects analysis $[F(1,29)=11.28$, $p<.01]$ and the items analysis $[F(1,30)=8.06, p=$ $.01]$. Simple-effects analyses indicated that facilitative priming was limited to rime primes, for which the priming effect was significant in both the subjects analysis $[F(1,29)=11.35, p<.01]$ and the items analysis $[F(1,30)=9.14, p<.01]$ (see Table 2$)$. Coda priming was not significant in either the subjects analysis $[F(1,29)=2.00, p>.05]$ or the items analysis $[F(1,30)=1.04, p>.05]$.

Naming latencies did not differ from Block 1 to Block 2 in either the subjects analysis $[F(1,29)=0.27, p>.05]$ or the items analysis $[F(1,54)=1.29, p>.05]$. Block did not interact significantly with any other factor in either the subjects or the items analysis (all $p \mathrm{~s}>.05$ ).

\section{Discussion}

Using a more conservative experimental design, Experiment 2 replicated the differential rime-priming effect of Experiment 1. Significant priming was observed only when the prime corresponded to an orthographic rime unit. The nonsignificance of the nonrime prime facilitation was notable, given that the prime comprised what a minority of linguists regard as a more likely internal subsyllabic unit, the coda. No evidence was found in this experiment that the coda corresponds to a unit of adult word recognition (see also Fudge, 1987).

More importantly, the current findings refute the possibility that the differential priming effect observed in Ex-

Table 2

Target Word Naming Latency (in milliseconds) in Experiment 2 as a Function of Prime Condition and Prime-Rime Unit Status

\begin{tabular}{lccccccc}
\hline & \multicolumn{3}{c}{ Unprimed } & & \multicolumn{3}{c}{ Primed } \\
\cline { 2 - 4 } \cline { 6 - 8 } Target Words & $M$ & $S D$ & Invalid & $M$ & $S D$ & Invalid \\
\hline Experimental & 555.43 & 90.96 & $6.9 \%$ & & 538.67 & 91.04 & $6.3 \%$ \\
Control & 534.85 & 84.85 & $4.8 \%$ & & 540.48 & 80.50 & $3.5 \%$ \\
\hline
\end{tabular}

Note-Invalid trials include out-of-range responses, voicebox malfunction, and reading errors. periment 1 was attributable to prime frequency effects. In Experiment 2, rime and nonrime primes were equivalent in terms of bigram frequency. The differential priming effect observed in both experiments is consistent with the view that orthographic rime units serve as functional units of word recognition, at least in low-frequency words.

\section{EXPERIMENT 3}

Again using the partial identity priming paradigm, in Experiment 3 the complementary hypothesis was testedthat is, that orthographic onsets serve as functional units of word recognition. In this experiment, experimental words had a two-letter onset unit and control words had single-letter onset units. As in Experiment 1, each subject saw each target word twice, once primed and once unprimed. However, in this experiment, words were primed by the first two letters of the word. Thus, the primes of the experimental words corresponded to onset units, but the primes of the control words did not correspond to any subsyllabic unit. In this experiment, onset primes were lower in bigram frequency than non-onset primes.

The onset hypothesis would predict that priming would facilitate word-naming times in the experimental words (in which the prime corresponded to the orthographic onset) more strongly than in the control words (in which the prime did not correspond to a subsyllabic unit). A bigram frequency account would predict weaker facilitative priming in the experimental words, the reverse of the orthographic onset account. A graphemic priming account would predict equal facilitation of both sets of words, since in both sets the prime consisted of the first two letters of the target word.

\section{Method}

Subjects. An independent sample of 28 students, all native English speakers, was recruited from the University of Queensland introductory psychology subject pool.

Materials. Experimental materials were derived from 56 lowand moderate-frequency four- and five-letter words (range 1-43; Kucera \& Francis, 1967). The 28 experimental words began with a consonant cluster (CC) onset, and the 28 control words contained a single-letter onset unit. Each of 28 word-initial bigrams occurred twice, to reduce opportunities for guessing. Experimental and control word sets were equivalent in terms of word frequency according to the Kučera and Francis (1967) word count $(M=11.50$ and 11.29, respectively), and word length was matched across experimental and control pairs (see Appendix 3). Experimental primes had lower overall bigram frequencies than did control primes $[t(14)=4.97$, $p<.05]$, with means of $6,320.07$ and $12,314.21$, respectively (Solso \& Juel, 1980). A similar result was observed using the Mayzner and Tresselt $(1965)$ count $[t(14)=6.88, p<.05, M=97.43$ and 218.07 , respectively].

The method of construction of the two parallel sets of test materials was the same as that described in Experiments 1 and 2, except that words were primed with the word-initial bigram. Half of the subjects received each set of experimental materials.

An independent set of 24 practice items was prepared in a similar manner. The order of these practice items was randomized. No 
practice item was repeated either within the practice trials or within the blocks of test trials. All subjects received the same practice trials, in the same order.

Procedure. The procedure was identical to that used in Experiment 1 .

\section{Results}

Again, only correct and valid trials with naming latencies of $2 \mathrm{sec}$ or less were used in the data analysis; 139 trials $(4.4 \%)$ were discarded.

Three-way prime (primed, unprimed) $\times$ prime onset status (experimental, control) $\times$ block $(1,2)$ analyses of variance were performed on mean naming latency scores for both subjects and items data. Primed words yielded significantly lower naming latencies than did unprimed words, in both the subjects analysis $[F(1,27)=12.30$, $p<.01]$ and the items analysis $[F(1,54)=33.51, p<$ $.001]$. Prime onset status was significant in the subjects analysis $[F(1,27)=6.07, p<.05]$, but not in the items analysis $[F(1,54)=1.72, p>.05]$. Both the prime and prime onset status effects were attributable to the significant prime $\times$ prime onset status interaction, which was obtained in both the subjects analysis $[F(1,27)=9.87$, $p<.01]$ and the items analysis $[F(1,54)=11.35, p=$ $.001]$. Simple-effects analyses indicated that the facilitatory effect of priming was limited to the items in which the primed bigram corresponded to an onset unit, in both the subjects analysis $[F(1,27)=22.81, p<.001]$ and the items analysis $[F(1,27)=34.73, p<.001]$ (see Table 3). Priming was not significant when the bigram primed did not correspond to a subsyllabic unit in either the subjects analysis $[F(1,27)=2.53, p>.05]$ or the items analysis $[F(1,27)=3.69, p>.05]$.

Shorter naming latencies were observed in Block 2 than in Block 1 , in both the subjects analysis $[F(1,27)=6.85$, $p<.05]$ and the items analysis $[F(1,54)=10.60, p<$ .01]. However, block did not interact significantly with any other factor in either the subjects or the items analysis (all $p s>.05$ ).

\section{Discussion}

The results of Experiment 3 paralleled those of Experiments 1 and 2 . Significant priming effects were obtained only when the prime corresponded to a subsyllabic unitin this case, the onset unit. The differential priming effect cannot be explained by graphemic priming, prime frequency, or practice effects. ${ }^{1}$

Table 3

Target Word Naming Latency (in milliseconds) in Experiment 3 as a Function of Prime Condition and Prime-Onset Unit Status

\begin{tabular}{lccccccc}
\hline & \multicolumn{3}{c}{ Unprimed } & & \multicolumn{3}{c}{ Primed } \\
\cline { 2 - 4 } \cline { 6 - 8 } Target Words & $M$ & $S D$ & Invalid & $M$ & $S D$ & Invalid \\
\hline Experimental & 563.20 & 54.44 & $5.2 \%$ & & 533.70 & 70.14 & $4.6 \%$ \\
Control & 563.14 & 57.33 & $3.8 \%$ & & 552.41 & 76.51 & $4.2 \%$ \\
\hline
\end{tabular}

Note-Invalid trials include out-of-range responses, voicebox malfunction, and reading errors.
The current research provides strong evidence that orthographic onsets and rimes serve as functional units of reading, at least in low- and moderate-frequency words, as first suggested by Treiman and Chafetz (1987). This proposal implies a hierarchical view of word recognition, at least in low- and moderate-frequency words. The letter string is initially parsed into onset and rime units, which are later synthesized. Word recognition that proceeds on the basis of sublexical rime units does not require a lexical mechanism. The ("ordered tree") hierarchical view of word recognition is implicit in much previous reading research; the notion of word recognition by analogy (Glushko, 1979) has invariably relied on an intuition that monosyllabic words are processed according to an initial onset-rime division. For instance, orthographic consistency is defined in terms of orthographic rime neighbors rather than orthographic neighbors per se. Thus, wave is viewed as an inconsistent word, since it activates orthographic neighbors with competing pronunciations (e.g., have). However, unless orthographic neighborhoods are defined in terms of rime neighbors, orthographic consistency becomes a meaningless concept. For instance, unless a hierarchical view is adopted, the regular consistent word hate must be classified as inconsistent, since hate would also activate its neighbors have and hare, in which the vowel is pronounced differently. All previous research investigating orthographic consistency effects has implicitly parsed words into orthographic onset and rime units (e.g., Andrews, 1982; Glushko, 1979; Seidenberg et al., 1984; Taraban \& McClelland, 1987). This onset-rime division is also implicit in Venezky's (1970) descriptions of consonant and positional influences on grapheme-phoneme correspondences.

The adoption of orthographic onset and rime as units of visual word recognition reduces the apparent inconsistency of English orthography to finite dimensions. The division of letter sequences into orthographic onset and rime units activates a more restricted range of alternative phonological encodings of a grapheme sequence than does nonprincipled processing. For instance, the orthographic rime -ear activates only two alternative pronunciations (hear, wear). The onset sequence $c h$ is similarly limited (chin, chute, chemist). Most onsets in English are, in fact, consistent. In contrast, the potential pronunciation of an arbitrary initial sequence such as bro- is relatively large (bro is pronounced differently in each of the following words: broth, brother, broil, brook, broom, broad, and brooch), although quite constrained when a combination of onset and rime pronunciation rules is used to provide a powerful set of "large-unit pronunciation rules" (e.g., $b r+o t h$ can only activate two possible pronunciations; see also Baron, 1979; Patterson \& Morton, 1985; Shallice \& McCarthy, 1985; Treiman \& Zukowski, 1988).

Because it independently postulates an ordered hierarchical syllable structure, the proposal that orthographic onset and rime units constitute functional units of reading provides a theoretically based rationale for findings 
that different segments of the word contribute differentially to exception and consistency effects (Taraban \& McClelland, 1987). There is at present no other a priori rationale for biasing spreading activation accounts in this way. Although it is possible that onset and rime units emerge as "hidden units" within connectionist accounts of reading (e.g., see Seidenberg, 1989), such phenomena remain to be simulated.

The current research was designed to provide converging evidence that orthographic onsets and rimes serve as functional units of reading (see Treiman \& Chafetz, 1987). In this it has succeeded. However, further work investigating the nature of subsyllabic orthographic units is clearly required. Research is currently underway investigating orthographic onset and rime priming as a function of target word frequency, whether the rime-priming effect is primarily orthographic or phonological (Bowey, 1990), and its emergence in children (Hansen \& Bowey, 1990). It is beyond the scope of the present paper to address these issues.

\section{REFERENCES}

ANDREws, S. (1982). Phonological recoding: Is the regularity effect consistent? Memory \& Cognition, 10, 565-575.

BARON, J. (1979). Orthographic and word-specific mechanisms in children's reading of words. Child Development, 50, 60-72.

Bowey, J. A. (1990). The nature of the orthographic rime unit. Manuscript in preparation.

Brown, G. D. A. (1987). Resolving inconsistency: A computational model of word naming. Journal of Memory \& Language, 26, 1-23.

Cномsкy, N., \& Halle, M. (1968). The sound pattern of English. New York: Harper and Row.

Claxton, G. L. (1974). Initial consonant groups function as units in word production. Language \& Speech, 17, 271-277.

Clements, G. N., \& KeYser, S. J. (1983). CV phonology. Cambridge, MA: MIT Press.

Coltheart, M. (1978). Lexical access in simple reading tasks. In G. Underwood (Ed.), Strategies of information processing (pp. 151216). London: Academic Press.

Coltheart, M. (1985). Cognitive neuropsychology and the study of reading. In M. I. Posner \& O. S. M. Martin (Eds.), Attention and performance (Vol. 11, pp. 3-37). Hillsdale, NJ: Erlbaum.

Cutler, A., Butterfield, S., \& Williams, J. N. (1987). The perceptual integrity of syllabic onsets. Journal of Memory \& Language, 26, 406-418.

DrewNOWSKI, A., \& HeAlY, A. F. (1977). Detection errors on the and and: Evidence for reading units larger than the word. Memory \& Cognition, 5, 636-647.

DrewnowsKı, A., \& HeAly, A. F. (1980). Missing -ing in reading: Letter detection errors on word endings. Journal of Verbal Learning \& Verbal Behavior, 19, 247-262.

FUDGE, E. (1987). Branching structure within the syllable. Journal of Linguistics, 23, 359-377.

Glushko, R. J. (1979). The organization and activation of orthographic knowledge in reading aloud. Journal of Experimental Psychology: Human Perception \& Performance, 5, 674-691.

Goswamı, U. (1986). Children's use of analogy in learning to read: A developmental study. Journal of Experimental Child Psychology, 42, 73-83.

HANSEN, J., BOWEY, J. A. (1990). Orthographic rimes as functional units of children's reading. Manuscript submitted for publication.

KAY, J., \& BisHOP, D. (1987). Anatomical differences between nose, palm, and $f(x)$, or the bxaly in question: Further dissection of the processes of sub-lexical spelling-sound translation. In $\mathbf{M}$. Coltheart (Ed.). Attention and performunce (Vol 12, pp. 449-469). Hillsdale. NJ: Erlbaum

KAY, J., MAR(EI., A (1981). One process, not two, in reading aloud Lexical analogies do the work of non-lexical rules. Quarierly Journal of Experimental Psychology, 33A. 397-413.

Kú̌era. J. . Francis. W. N. (1967). Computational analysis of presens day American English. Providence. RI: Brown University Press.

MacKAY, D. G. (1972). The structure of words and syllables: Evidence from errors in speech. Cognitive Psychology. 3, 210-227.

MARCEL. T. (1980). Surface dyslexia and beginning reading: A revised hypothesis of the pronunciation of print and its impairments. In M. Coltheart, K. Patterson, \& J. C. Marshall (Eds.), Deep dyslexia (pp. 227-258). London: Routledge \& Keagan Paul

Mayzner, M. S., \& Tresset.t. M. E. (1965). Tables of single-letter and digram frequency counts for various word-length and letter-position combinations. Psychonomic Monograph Supplements, 1(2, Whole No. 2), 13-32

Mayzner, M. S., Tresselt, M. E., Wolin, B. R. (1965). Tables of trigram frequency counts for various word-length and letter-position combinations. Psychonomic Monograph Supplements, 1(3, Whole No. 3), 33-78

MCClelland, J. L., \& Rumel.hart, D. E. (1981). An interactive activation model of context effects in letter perception: 1. An account of basic findings. Psychological Review, 5, $375-407$

Patterson, K. E. . Morton, J. (1985). From orthography to phonology: An attempt at an old interpretation. In K. E. Patterson, J. C. Marshall, \& M. Coltheart (Eds.), Surface dyslexia (pp. 335-359). London: Erlbaum.

Rosson, M. B. (1985). The interaction of pronunciation rules and lexical representations in reading aloud. Memory \& Cognition, 13, $90-99$.

SEIDENBERG, M. S. (1989). Visual word recognition and pronunciation: A computational model and its implications. In W. D. MarslenWilson (Ed.), Lexical representation and process. Cambridge. MA: MIT Press.

Seidengerg, M. S., Waters, G. S., Barnes, M. A. . Tanenhaus, M. K. (1984). When does irregular spelling or pronunciation influence word recognition? Joumal of Verbal Learning \& Verbal Behavior. 23, 383-404

Shallice, T., \& Mc Carthy, R. (1985). Phonological reading: From patterns of impairment to possible procedures. In K. E. Patterson, J. C. Marshall, \& M. Coltheart (Eds.), Surface dyslexia (pp. 361397). London: Erlbaum

Solso, R. L., B^rbuto, P. F., JR., Juel, C. L. (1979). Bigram and trigram frequencies and versatilities in the English language. Behavior Research Methods \& Instrumentation, 11, 475-484.

SoLso, R. L., JUEL, C. L. (1980). Positional frequency and versatility of bigrams for two- through nine-letter English words. Behavior Research Methods \& Instrumentation, 12, 297-343.

Taraban, R., McClelland, J. L. (1987). Conspiracy effects in word pronunciation. Journal of Memory \& Language, 26, 608-631.

Treiman, R. (1983). The structure of spoken syllables: Evidence from novel word games. Cognition, 15, 49-74.

Treiman, R. (1985). Onsets and rimes as units of spoken syllables: Evidence from children. Journal of Experimental Child Psychology, 39. 161-181.

Treiman, R., Chafetz, J. (1987). Are there onset- and rime-like units in printed words? In M. Coltheart (Ed.), Attention and performance (Vol. 12, pp. 281-298). Hillsdale, NJ: Erlbaum.

Treiman, R., \& Danis, C. (1988). Short-term memory errors for spoken syllables are affected by the linguistic structure of the syllables. Joumal of Experimental Psychology: Learning, Memory, \& Cognition, 14, 145-152.

Treiman, R., Zukowskı, A. (1988). Units in reading and spelling. Journal of Memory \& Language, 27, 466-477.

VENEZKY, R. L. (1970). The structure of English orthography. The Hague: Mouton 


\section{NOTE}

1. The CC primes used in Experiment 3 activated consistently pronounced onset units. It may be objected that the control consonantvowel (CV) primes activated alternate pronunciations, and thus that the results of Experiment 3 cannot be interpreted as indicating selective onset priming effects. However, it is unlikely that the selective onset priming effect observed in Experiment 3 can be attributed wholly to the activation of alternate pronunciations by the $\mathrm{CV}$ control primes, for two reasons. First, the activation of multiple pronunciations would proba- bly lead to inhibitory priming in the control condition, whereas nonsignificant effects were obtained for the CV primes in Experiment 3 (parallel to those obtained in Experiments 1 and 2). Second, orthographic onsetunit effects are not limited to the priming task. Unpublished evidence (Bowey, 1990) indicates that, in a word-naming task, subjects' naming times are slowed by case alterations that interfere with onset-unit processing, but not by case alterations that leave the onset unit intact. Thus, SHawl is named as fast as shawl, but SHred is named more slowly than shred. Such an effect shows that orthographic onsets are processed as units in a task that cannot involve prior phonological priming.

\section{APPENDIX 1}

Target Words Used in Experiment 1

\begin{tabular}{|c|c|c|c|}
\hline \multicolumn{2}{|c|}{ Experimental } & \multicolumn{2}{|c|}{ Control } \\
\hline Target & Frequency & Target & Frequency \\
\hline hail & 10 & pray & 12 \\
\hline meek & 10 & scar & 10 \\
\hline burn & 15 & trot & 12 \\
\hline curb & 13 & blew & 12 \\
\hline pine & 14 & snap & 12 \\
\hline void & 10 & grim & 14 \\
\hline rope & 15 & shed & 11 \\
\hline roar & 13 & drag & 15 \\
\hline hire & 15 & spit & 11 \\
\hline gaze & 12 & knit & 10 \\
\hline bite & 10 & clue & 15 \\
\hline coin & 10 & plea & 11 \\
\hline tide & 11 & swim & 15 \\
\hline vain & 10 & drum & 11 \\
\hline heap & 14 & spin & 5 \\
\hline tune & 10 & spur & 13 \\
\hline woke & 14 & grin & 13 \\
\hline duke & 11 & clap & 1 \\
\hline boil & 12 & grey & 12 \\
\hline dice & 14 & slug & 10 \\
\hline
\end{tabular}

Note-Frequency values are from Kucera and Francis (1967).

\section{APPENDIX 2}

Target Words Used in Experiment 2

\begin{tabular}{|c|c|c|c|}
\hline \multicolumn{2}{|c|}{ Experimental } & \multicolumn{2}{|c|}{ Control } \\
\hline Target & Frequency & Target & Frequency \\
\hline swig & 2 & deft & 2 \\
\hline blob & 4 & weld & 4 \\
\hline glee & 3 & lick & 3 \\
\hline crib & 5 & bump & 5 \\
\hline clog & 2 & sect & 2 \\
\hline grub & 2 & wisp & 2 \\
\hline trot & 12 & $\operatorname{tank}$ & 12 \\
\hline drum & 11 & cult & 11 \\
\hline slug & 10 & wept & 9 \\
\hline clip & 6 & dusk & 9 \\
\hline grim & 14 & yelp & 2 \\
\hline plea & 11 & huff & 10 \\
\hline bred & 1 & dent & 2 \\
\hline slop & 2 & gust & 2 \\
\hline flag & 16 & bulk & 16 \\
\hline flaw & 3 & sill & 4 \\
\hline
\end{tabular}

Note-Frequency values are from Kucera and Francis (1967). 


\section{APPENDIX 3}

Target Words Used in Experiment 3

\begin{tabular}{|c|c|c|c|c|c|c|c|}
\hline \multicolumn{4}{|c|}{ Experimental } & \multicolumn{4}{|c|}{ Control } \\
\hline Target & Frequency & Target & Frequency & Target & Frequency & Target & Frequency \\
\hline brand & 17 & brave & 24 & birch & 2 & bitch & 6 \\
\hline blot & 6 & blow & 33 & boil & 12 & bolt & 10 \\
\hline clash & 5 & cliff & 11 & catch & 43 & caste & 3 \\
\hline crow & 2 & crop & 20 & colt & 18 & coil & 6 \\
\hline drug & 24 & drag & 15 & darn & 3 & dank & 1 \\
\hline flag & 16 & flip & 4 & fold & 7 & folk & 34 \\
\hline fray & 1 & frog & 1 & fuse & 5 & fuss & 4 \\
\hline grim & 14 & grab & 16 & gang & 22 & gaze & 12 \\
\hline plump & 4 & plead & 5 & patch & 13 & paint & 37 \\
\hline prose & 14 & print & 18 & purse & 14 & punch & 5 \\
\hline slum & 8 & slab & 9 & sack & 8 & sail & 12 \\
\hline smog & 1 & smug & 7 & sect & 2 & seam & 9 \\
\hline snap & 12 & snag & 3 & sigh & 11 & silk & 12 \\
\hline trim & 20 & trot & 12 & tuck & 2 & turf & 3 \\
\hline
\end{tabular}

Note-Frequency values are from Kučera and Francis (1967).

(Manuscript received July 28, 1989;

revision accepted for publication January 3,1990 .) 